\title{
Analisis Kinerja Jaringan VANET dengan Model Propagasi Free Space dan Two Ray Ground Pada Routing AODV
}

\author{
Adam Tedy Agustin ${ }^{\star 1}$, Denar Regata $\mathbf{A k b i}^{2}$, Diah Risqiwati ${ }^{3}$ \\ 1,2,3 Teknik Informatika/Universitas Muhammadiyah Malang \\ adamtedy023@gmail.com¹, dnarregata@umm.ac.id², diah.rizqiwati@gmail.com³
}

\begin{abstract}
Abstrak
VANET ialah salah satu jenis jaringan Ad Hoc yang berfungsi sebagai jaringan wireless dengan berberapa mobile node yang tidak mempunyai router tetap. Setiap node ini dapat berfungsi sebagai router yang dapat mencari dan menangani jalur ke node yang lain dalam suatu jaringan. Setiap node pada jaringan berupa mobile sehingga topologi dari jaringannya senantiasa berganti. Pada suatu jaringan, protokol routing yakni hal yang banyak berdampak atas kinerja jaringan tersebut. Setiap model propagasi tentu akan memiliki kemampuan dan karakteristik yang berbeda, oleh karena itu perlu dilakukan penelitian terhadap beberapa model propagasi pada tempat yang ditentukan yang kemudian akan mempengaruhi kinerja QoS pada jaringan VANET. Simulasi mobilitas dilakukan berdasarkan skenario lingkungan urban yaitu sekitar Balai Kota Malang. Penelitian ini mengaplikasikan SUMO sebagai mobile simulator dan NS-2 selaku network simulator dengan protokol reaktif jenis AODV sebagai protokol routing yang digunakan serta menggunakan model propagasi Free Space dan Two Ray Ground sebagai pembanding yang ada pada NS-2. Dalam penelitian ini melakukan analisis QoS dengan parameter yang di uji adalah End to End Delay, Jitter, Packet Delivery Ratio dan Throughput. Setelah data terkumpul, dilakukan analisis dengan melihat QoS antar propagasi yang diuji. Model propagasi Free Space memiliki waktu delay yang lebih kecil dengan nilai rata-rata $0.1136 \mathrm{~ms}$ dari pada propagasi Two Ray Ground yang memiliki nilai 0.1696 ms. Untuk jumlah paket yang diterima dengan sukses propagasi Free Space lebih baik dengan nilai rata-rata throughput 482.06 kbps dibandingkan dengan propagasi Two Ray Ground. Hasil dari pengujian dan analisis membuktikan bahwa propagasi Free Space adalah model yang tepat pada jaringan VANET yang digunakan pada lingkungan urban.
\end{abstract}

Kata Kunci: Ad hoc, VANET, AODV, Free Space, Two Ray Ground

\begin{abstract}
VANET is one type of Ad Hoc network that serves as a wireless network with several mobile nodes that do not have a fixed router. Each of these nodes can function as a router that can search and handle paths to other nodes within a network. Each node on the network is mobile so that the topology of the network is constantly changing. On a network, the routing protocol is something that has a lot of impact on the performance of the network. Each propagation model will certainly have different capabilities and characteristics therefore it is necessary to research some propagation models in the specified place which will then affect QoS performance on the VANET network. Mobility simulation is done based on urban environment scenario that is around Malang City Hall. This research applies SUMO as mobile simulator and NS-2 as network simulator with AODV type reactive protocol as routing protocol which is used and use propagation model of Free Space and Two Ray Ground as comparison in NS-2. In this research to do QoS analysis with parameters in the test is End to End Delay, Jitter, Packet Delivery Ratio and Throughput. After the data collected, analysis is done by looking at the QoS between the propagation tested. The Free Space propagation model has a smaller delay time with an average of $0.1136 \mathrm{~ms}$ than on the Two Ray Ground propagation which has a value of $0.1696 \mathrm{~ms}$. For the number of packets received successfully Free Space propagation is better with an average value of $482.06 \mathrm{kbps}$ throughput compared to Two Ray Ground propagation. The results of testing and analysis prove that Free Space propagation is the right model on the VANET network used in urban environments.
\end{abstract}

Keywords: Ad hoc, VANET, AODV, Free Space, Two Ray Ground 


\section{Pendahuluan \\ 1.1. Latar Belakang}

Jumlah kecelakaan pada kendaaraan terus mengalami peningkatan setiap tahunnya [1]. Bahkan banyak orang terluka dan korban mati terjadi di jalan raya diakibatkan oleh kecelakaan kendaraan. Salah satu upaya untuk mengurangi jumlah kecelakaan yaitu dengan memanfaatkan sistem jaringan VANET. VANET merupakan singkatan dari Vehicular Ad Hoc Network dimana setiap node dalam jaringan merupakan kendaraan seperti mobil. VANET bertujuan membantu kendaraan-kendaraan untuk dapat saling berkomunikasi dan memelihara jaringan komunikasi. Ada beberapa jenis komunikasi pada VANET seperti V2V (Vehicle to Vehicle), V2I (Vehicle to Infrastructure), dan I2I (Infrastructure to Infrastructure) [2].

VANET dapat meningkatkan keamanan dalam berkendara. Dengan VANET setiap kendaraan akan dapat saling bertukar informasi tentang kondisi lalu-lintas di sekitarnya, informasi tersebut dapat berupa informasi kemacetan, kecelakaan dan informasi penting lainnya.

Dalam penerapannya, kinerja VANET sangat dipengaruhi oleh model propagasi. Model propagasi tidak dapat digunakan disemua tempat karena mempunyai karakteristik yang berbedabeda. Seperti model propagasi Free Space, model ini merepresentasikan jangkauan komunikasi dari perangkat komunikasi sebagai suatu lingkaran yang melingkupi pemancar dan paket-paket akan diterima, jika receiver berada di cakupan lingkaran tersebut. Sedangkan model propagasi Two Ray Ground memodelkan perambatan sinyal pada media nirkabel tidak hanya sebagai suatu saluran langsung (LOS) antara pemancar dan penerima, namun juga mengikutsertakan saluran pantulan permukaan (ground reflection) perambatan sinyal antara pemancar dan penerima [3]. Hal ini menyebabkan VANET tidak dapat menggunakan model propagasi yang sama disetiap tempat, oleh karena itu perlu dilakukan penelitian terhadap beberapa model propagasi pada tempat yang ditentukan yang nantinya akan mempengaruhi kinerja VANET [4].

Dalam sebuah jaringan, protokol routing merupakan hal yang sangat berpengaruh terhadap kinerja jaringan tersebut. Begitu pula dalam jaringan VANET, terdapat banyak protokol routing yang dapat diimplementasikan pada jaringan ini. Salah satunya adalah protokol routing AODV (Ad hoc On demand Distance Vector). Protokol routing AODV bersifat reaktif yang artinya hanya melakukan proses pembentukan rute pada saat dibutuhkan. Setiap kali pencarian rute, AODV hanya menemukan satu pilihan rute atau unipath. Apabila terjadi kegagalan rute, maka AODV akan mengulang proses pencarian rute [5].

Dalam Tugas Akhir ini, penulis akan melakukan analisis kinerja jaringan VANET dengan model propagasi Free Space dan Two Ray Ground pada protokol routing AODV. Untuk menganalisis kinerja dari kedua model propagasi tersebut akan dilakukan secara simulasi pada lingkungan urban dengan skenario perubahan jumlah node dan beberapa parameter yang akan di analisis pada saat proses pengujian, diantaranya packet delivery ratio, throughput, end to end delay, dan jitter.

\subsection{Landasan Teori}

\subsubsection{Jaringan Ad-Hoc}

Jaringan Ad Hoc adalah suatu jaringan dimana topologinya tidak direncanakan dan tidak tetap. Perlu ditambahkan kata Wireless, yang berarti node menggunakan interface Wireless untuk berkomunikasi, mobile node yang berarti bahwa node dapat berpindah posisi. Multi-Hop node berarti bahwa node dapat berkomunikasi dengan node lain secara tidak langsung dengan menggunakan node terdekat sebagai penghubung. Pada jaringan Ad-Hoc mempunyai 7 jenis jaringan [6], yaitu :

1. WANET (Wireless Ad Hoc Network)

2. MANET (Mobile Ad Hoc Network)

3. VANET (Vehicular Ad Hoc Network)

4. SPANs (Smart Phone Ad Hoc Network)

5. iMANETs (Internet Based Mobile Ad Hoc Netwok)

6. Military / Tactical MANETs

7. SPAN (Self Powered Ad Hoc Network)

\subsubsection{Karakteristik VANET}

VANET memiliki beberapa karakteristik yang lebih unggul dibanding dengan jaringan Ad Hoc lainnya, seperti [7]:

1. Memiliki topologi dinamis yang sangat tinggi.

REPOSITOR, Vol. 1, No. 2, Desember 2019: 69-78 
2. Jaringan yang sering terputus.

3. Pemodelan dan prediksi mobilitas node.

4. Model mobilitas sangat bervariasi dalam bentuk lingkungan yang berbeda-beda.

5. Batasan delay yang sulit.

6. Interakasi dengan sensor on-board pada sebuah kendaraan.

\subsubsection{Model Propagasi}

Salah suatu bagian penting dalam jaringan VANET adalah pemilihan model propagasi yang akan digunakan untuk memprediksi besar kecilnya nilai daya sinyal yang diterima pada jarak tertentu dari pemancar. Lapisan fisik setiap nodal mempunyai nilai ambang batas daya minimal penerimaan sinyal. Jika paket diterima dengan kondisi dibawah nilai ambang batas, maka paket tersebut dianggap sebagai paket yang rusak. Berikut merupakan berbagai model propogasi [8].

\subsubsection{Propagasi Free Space}

Pada model propagasi Free Space ini digunakan untuk memperkirakan kekuatan suatu sinyal yang diterima saat pemancar dan penerima tidak adanya penghalang (clear, unobstructued line-of-sight). Penggunaan propagasi ini termasuk pada skala besar yang dapat memprediksikan kekuatan power yang diterima menurun sejalan dengan kenaikan power pada jarak antara pemancar dan penerima ( $T$-R separation). Model ini pun melakukan komunikasi data pada sekitar lingkaran transmitter. Jika receiver berada di lingkaran tersebut, maka paket akan diterima dan sebaliknya.

\subsubsection{Propagasi Two Ray Ground}

Model propasi ini memodelkan perambatan sinyal pada media nirkabel tidak hanya sebagai suatu saluran langsung (LOS) antara pemancar dan penerima, sebagaimana dimodelkan pada Model propagasi free space, namun juga mengikutsertakan saluran pantulan permukaan (ground reflection) perambatan sinyal antara pemancar dan penerima. Pada model propagasi ini permukaan bumi dianggap sebagai permukaan yang datar sehingga sinyal yang diterima pada penerima merupakan hasil penjumlahan antara komponen sinyal yang merambat pada saluran langsung dan komponen sinyal yang merambat pada saluran terpantulkan (ground reflected). Model propagasi two-ray ground reflection ini tidak memberikan hasil yang akurat jika dimodelkan untuk transmisi jarak dekat karena adanya osilasi yang disebabkan oleh kombinasi konstruktif dan destruktif dari gelombang-gelombang yang merambat pada saluran yang berbeda.

\subsubsection{Protocol AODV}

AODV merupakan protocol routing yang bersifat reaktif. Protocol ini bersifat reaktif karena protocol ini mulai bekerja saat ada permintaan dari source node untuk mencari tahu jalur-jalur yang akan digunakan untuk mengirimkan pesan ke node tujuan. AODV akan berusaha untuk menemukan jalur yang tidak ada loop dan menemukan jalur terpendek untuk menuju node tujuan [9].

Seperti yang telah dijelaskan sebelumnya, AODV akan bekerja ketika ada permintaan dari source node untuk menemukan rute menuju destination node karena akan ada pengiriman pesan. Untuk menemukan jalur yang terbaik bagi source node, maka AODV akan melakukan route discovery dengan menyebarkan Route Request (RREQ) ke semua node yang bersebelahan dengan source node. Node tetangga tersebut akan mengirimkan RREQ ke node tetangganya lagi hingga berakhir di node tujuan. Setelah RREQ sampai ke node tujuan, maka node tujuan akan membalas pesan RREQ dengan Route Reply (RREP). Jalur yang akan dipilih tentunya rute dengan jarak terpendek dan cost yang lebih rendah dibandingkan dengan jalur yang lainnya.

\subsubsection{SUMO}

SUMO (Simulation of Urban MObility) adalah perangkat lunak berbasis open source dan merupakan simulator pergerakan kendaraan serta lalu lintas jalan yang sangat portable, sehingga dapat menangani jaringan yang besar. SUMO di kembangkan oleh Institute of Transportation System di German Aerospace Center [10]. Hal ini user dapat mensimulasikan bagaimana request lalu lintas kendaraan yang diberikan dengan jaringan dan peta lalu lintas tertentu. Ada beberapa palet komponen yang tersedia pada SUMO, seperti [10]: 
1. SUMO: perintah baris (command line) simulasi.

2. GUISIM: menjalankan simulasi dengan antarmuka grafis.

3. NETCONVERT: komponen yang berfungsi sebagai import sebuah jaringan.

4. JTRROUTER: pengarahan generator berdasrkan rasio putar pada persimpangan lalu lintas.

5. DUAROUTER: pengarahan generator berdasarkan user (dinamis).

6. DFROUTER: pengarahan generator dengan menggunakan detector data.

\section{Metode Penelitian}

Pada bagian ini membahas tentang perancangan sistem. Perancangan sistem yang akan dibahas adalah tentang skenario simulasi, alur flowchart, serta parameter yang digunakan saat simulasi.

A. Perancangan Simulasi Jaringan

Pada bagian ini menjelaskan perancangan simulasi yang akan dianalisa. Simulasi dilakukan dengan posisi node yang tidak beraturan atau acak. Node yang dibuat adalah dengan menggunakan komunikasi data jaringan wireless. Node juga bergerak secara acak, tidak terpacu dalam kondisi tertentu serta jumlah node bervariasi. Paket yang dikirim dari satu node ke node yang lainnya akan ditentukan dalam skenario yang sudah dibuat sesuai dengan kebutuhan. Selama proses pengiriman paket terjadi akan dicatat setiap aktivitas QoS (Quality of Service) kedalam file log yang berformat *.tr. Setelah proses pengiriman paket selesai maka akan dilakukan analisa terhadap file log tersebut agar dapat diketahui QoS pada masing - masing model propagasi.

Pengujian akan dilakukan dengan memulai pengiriman paket data baik pada model propagasi Two Ray Ground maupun propagasi Free Space. Kemudian akan dilakukan analisa perbandingan QoS pada kedua model propagasi dengan membuat tabel perbandingan. Adapun variabel yang akan diuji, meliputi:

1. Packet Delivery Ratio.

2. Throughput.

3. End to End Delay.

4. Jitter.

B. Skenario Simulasi

Skenario yang digunakan untuk analisis QoS jaringan VANET pada Model propagasi Two Ray Ground dan Free Space adalah dengan membuat variasi node lingkungan simulasi yang sama. Dengan begitu akan bisa dibandingan antara model propagasi Two Ray Ground dan Free Space. Beberapa parameter yang akan digunakan dalam merancang skenario, seperti pada Tabel 1.

Tabel 1. Skenario Simulasi

\begin{tabular}{lll}
\hline \multicolumn{1}{c}{ Kriteria } & \multicolumn{1}{c}{ Skenario 1 } & \multicolumn{1}{c}{ Skenario 2 } \\
\hline Kecepatan Node & Kecepatan Acak & Kecepatan Tetap \\
Lingkungan Area & Urban (Balai Kota Malang) & Urban (Balai Kota Malang) \\
Variasi Node & 15, 30, 45 node & $15,30,45$ node \\
Waktu Simulasi & 100 detik & 100 detik \\
Model Propagasi & Two Ray Ground dan Free & Two Ray Ground dan Free \\
& Space & Space \\
Parameter QoS & Jitter, Packet Delivery Ratio, & Jitter, Packet Delivery Ratio, \\
& Delay, Throughput & Delay, Throughput \\
\hline
\end{tabular}

Pada tahap ini peneliti mempunyai 2 skenario berbeda yang nantinya akan memberikan hasil yang berbeda. Pada skenario 1 kecepatan pergerakan node akan acak selama simulasi berjalan dan kecepatan pergerakan pada skenario 2 pun acak selama waktu simulasi berjalan, tetapi ada suatu waktu kondisi tertentu kecepatan node akan sama atau tetap. Kemudian akan dicari QoS di masing- masing skenario yang telah ditentukan dengan model propagasi Two Ray Ground dan Free Space.

\section{Flowchart}

Flowchart dari simulasi yang akan dilakukan pada jaringan VANET pada model propagasi Two Ray Ground dan Free Space dengan menggunakan routing protocol AODV adalah sebagai Gambar 1.

REPOSITOR, Vol. 1, No. 2, Desember 2019: 69-78 


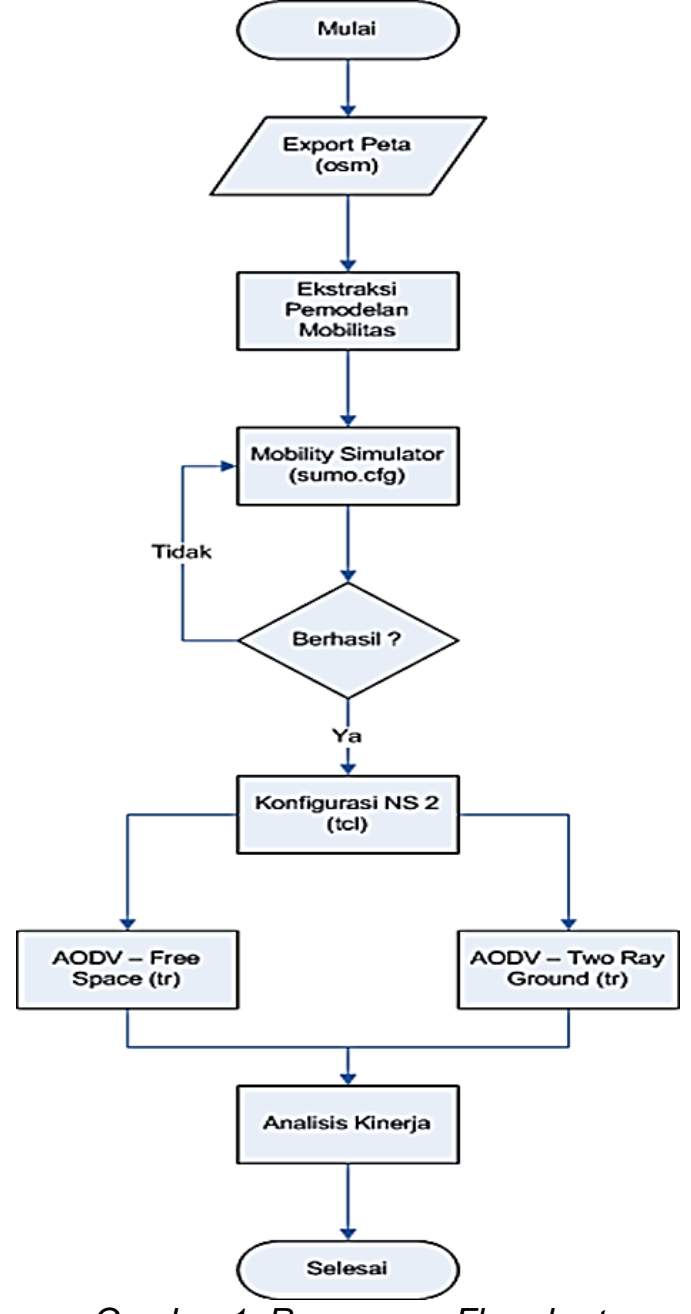

Gambar 1. Rancangan Flowchart

D. Parameter Simulasi

Dalam penelitian ini, metode yang digunakan adalah simulasi dengan menggunakan NS2. Pada penelitian ini kecepatan dan pergerakan node sudah ditentukan sesuai dengan konfigurasi pada software SUMO sehingga node dapat bergerak sesuai dengan skenario. Model ini dapat membuat node memilih tujuan yang sudah ditetapkan.

Dalam skenario ini area simulasi dibuat berukuran 4000×3000 m2 dan hasil dari konversi lingkungan yang sudah ditetapkan yaitu urban Balai Kota Malang. Area simulasi dibuat seperti ini agar node dapat bebas bergerak dan secara benar sesuai skenario yang ditentukan. Tabel 2 berikut ini adalah parameter yang digunakan dalam simulasi.

Tabel 2. Paramater Simulasi

\begin{tabular}{cc}
\hline Parameter & Nilai \\
\hline Tipe Kanal & Wireless Channel \\
Model Propagasi & Two Ray Ground dan Free Space \\
Tipe Network Interface & Wireless \\
Tipe MAC & IEEE 802.11 \\
Maksimal Paket dalam Antrian & 50 \\
Tipe Antrian & Drop Tail \\
Tipe Antena & OmniAntenna \\
Waktu Simulasi & 100 detik \\
Routing Protocol & AODV \\
Model Pergerakan Node & Random Way Point \\
Kecepatan Node & Sesuai skenario \\
\hline
\end{tabular}




\section{Hasil Penelitian dan Pembahasan}

Bab ini akan membahas mengenai implementasi dan pengujian sistem. Melalui pengujian sistem ini akan diketahui keberhasilan dan kekurangan sistem yang telah dibuat. Dalam penerapannya, sistem ini menggunakan software SUMO dan NS-2. Selain itu, sistem ini menggunakan OS Backbox untuk menjalankan simulator. Peneliti menggunakan Bahasa Pemrograman perl pada OS Backbox untuk mengambil data QoS tersebut. Pengambilan data akan dilakukan sesuai dengan skenario perencanaan simulasi yang telah ditentukan dengan menggunakan script tcl. Dalam penelitian ini alur pengujian dilakukan dengan 2 skenario yang berbeda dengan routing AODV menggunakan Model Propagasi Two Ray Ground dan Free Space. Dari percobaan yang dilakukan akan menghasilkan data sebanyak 12 data dan akan ditampilkan dalam bentuk sebuah Tabel 3, Tabel 4, Tabel 5, Tabel 6, serta Gambar 2, Gambar 3, Gambar 4, dan Gambar 5.

Tabel 3. QoS Skenario 1 pada Propagasi Two Ray Ground

\begin{tabular}{cccccc}
\hline No & $\begin{array}{c}\text { Jumlah } \\
\text { Node }\end{array}$ & EED $(\mathrm{ms})$ & Jitter $(\mathrm{ms})$ & PDR $(\%)$ & $\begin{array}{c}\text { Throughput } \\
\text { (kbps) }\end{array}$ \\
\hline 1 & 15 & 0.1413 & 0.1413 & 0.9925 & 527.72 \\
2 & 30 & 0.1780 & 0.1780 & 0.9836 & 357.91 \\
3 & 45 & 0.1894 & 0.1895 & 0.9533 & 209.68 \\
\hline
\end{tabular}

Tabel 4. QoS Skenario 1 pada Propagasi Free Space

\begin{tabular}{cccccc}
\hline No & $\begin{array}{c}\text { Jumlah } \\
\text { Node }\end{array}$ & EED $(\mathrm{ms})$ & Jitter $(\mathrm{ms})$ & PDR $(\%)$ & $\begin{array}{c}\text { Throughput } \\
(\mathrm{kbps})\end{array}$ \\
\hline 1 & 15 & 0.120000 & 0.120006 & 0.998786 & 702.15 \\
2 & 30 & 0.120049 & 0.120049 & 0.998786 & 701.85 \\
3 & 45 & 0.100730 & 0.100790 & 0.975320 & 42.18 \\
\hline
\end{tabular}

Tabel 5. QoS Skenario 2 pada Propagasi Two Ray Ground

\begin{tabular}{cccccc}
\hline No & $\begin{array}{c}\text { Jumlah } \\
\text { Node }\end{array}$ & EED $(\mathrm{ms})$ & Jitter $(\mathrm{ms})$ & PDR $(\%)$ & $\begin{array}{c}\text { Throughput } \\
\text { (kbps) }\end{array}$ \\
\hline 1 & 15 & 0.1422 & 0.1422 & 0.9929 & 530.45 \\
2 & 30 & 0.1754 & 0.1754 & 0.9827 & 382.78 \\
3 & 45 & 0.1908 & 0.1908 & 0.9564 & 213.05 \\
\hline
\end{tabular}

Tabel 6. QoS Skenario 2 pada Propagasi Free Space

\begin{tabular}{cccccc}
\hline No & $\begin{array}{c}\text { Jumlah } \\
\text { Node }\end{array}$ & EED $(\mathrm{ms})$ & Jitter $(\mathrm{ms})$ & PDR $(\%)$ & $\begin{array}{c}\text { Throughput } \\
\text { (kbps) }\end{array}$ \\
\hline 1 & 15 & 0.1422 & 0.1422 & 0.9929 & 530.45 \\
2 & 30 & 0.1754 & 0.1754 & 0.9827 & 382.78 \\
3 & 45 & 0.1908 & 0.1908 & 0.9564 & 213.05 \\
\hline
\end{tabular}

\subsection{Perbandingan QoS}

Berikut ini adalah hasil dari perbandingan QoS dengan melakukan percobaan sebanyak 12 kali dengan skenario yang sudah ditentukan sebelumnya.

\subsection{Analisa Grafik Perbandingan}

Berikut ini adalah hasil dari perbandingan QoS dengan melakukan percobaan sebanyak 12 kali dengan skenario yang sudah ditentukan sebelumnya.

Pada Gambar 2 merupakan hasil nilai EED yang telah melewati tahap pengambilan data QoS. Dapat dinyatakan bahwa nilai EED pada propagasi Free Space lebih rendah dibanding Two Ray Ground pada kedua skenario tersebut. Setiap skenario antara kedua propagasi tersebut nilai EED mengalami sedikit perubahan. Pada propagasi Two Ray Ground mendapati peningkatan nilai EED setiap penambahan node. Hal ini berbeda dengan propagasi Free Space yang cenderung stabil dan mengalami penurunan ketika penambahan node. Adapun selisih nilai EED pada kedua propagasi setiap variasi node yang ditentukan, diantaranya pada 15 node: 0.021294 $\mathrm{ms}, 30$ node: $0.057987 \mathrm{~ms}$, dan 45 node: $0.08867 \mathrm{~ms}$. 


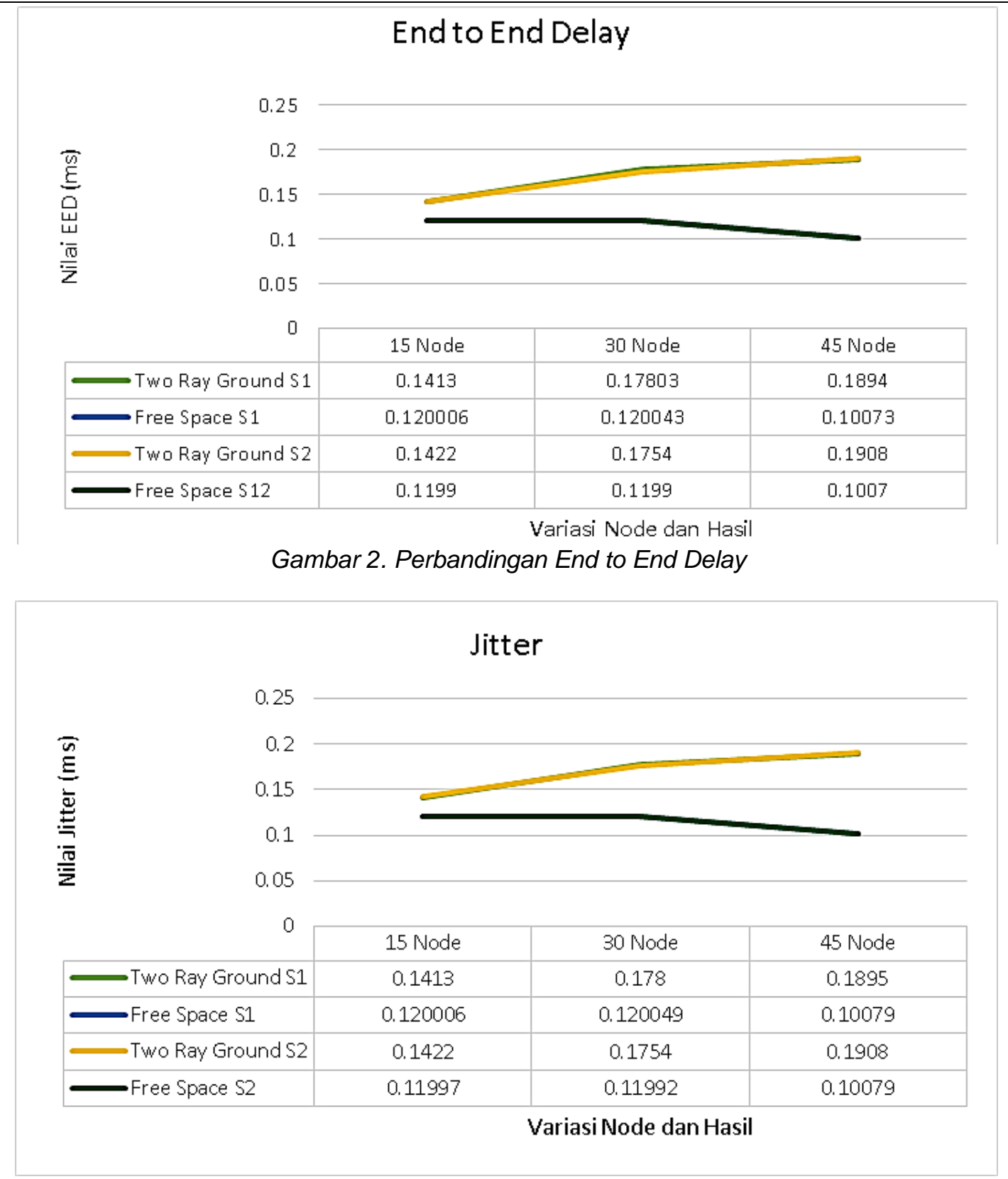

\section{Gambar 3. Perbandingan Jitter}

Pada Gambar 3 merupakan hasil nilai jitter yang telah melewati tahap pengambilan data QoS. Dapat dinyatakan bahwa nilai jitter mempunyai kemiripan dengan nilai EED. Pada propagasi Free Space juga mempunyai grafik lebih stabil dibanding Two Ray Ground. Adapun selisih nilai Jitter pada kedua propagasi setiap variasi node yang ditentukan, diantaranya pada 15 node : $0.021294 \mathrm{~ms}, 30$ node : $0.057951 \mathrm{~ms}$, dan 45 node : $0.08871 \mathrm{~ms}$.

Pada Gambar 4 merupakan QoS Packet Delivery Ratio yang dapat dinyatakan bahwa kedua propagasi tersebut mempunyai kesamaan yang sama yaitu, grafik PDR tersebut cenderung menurun ketika node semakin banyak. Akan tetapi nilai PDR propagasi Free Space lebih tinggi dibanding dengan Two Ray Ground. Skenario yang ditentukan juga berpengaruh pada propagasi Two Ray Ground yang mendapatkan nilai PDR yang berbeda, tetapi untuk propogasi Free Space tidak berpengaruh. Adapun selisih nilai PDR pada kedua propagasi setiap variasi node yang ditentukan, diantaranya pada 15 node : $0.0062 \%$, 30 node : $0.0151 \%$, dan 45 node : $0.022 \%$. 


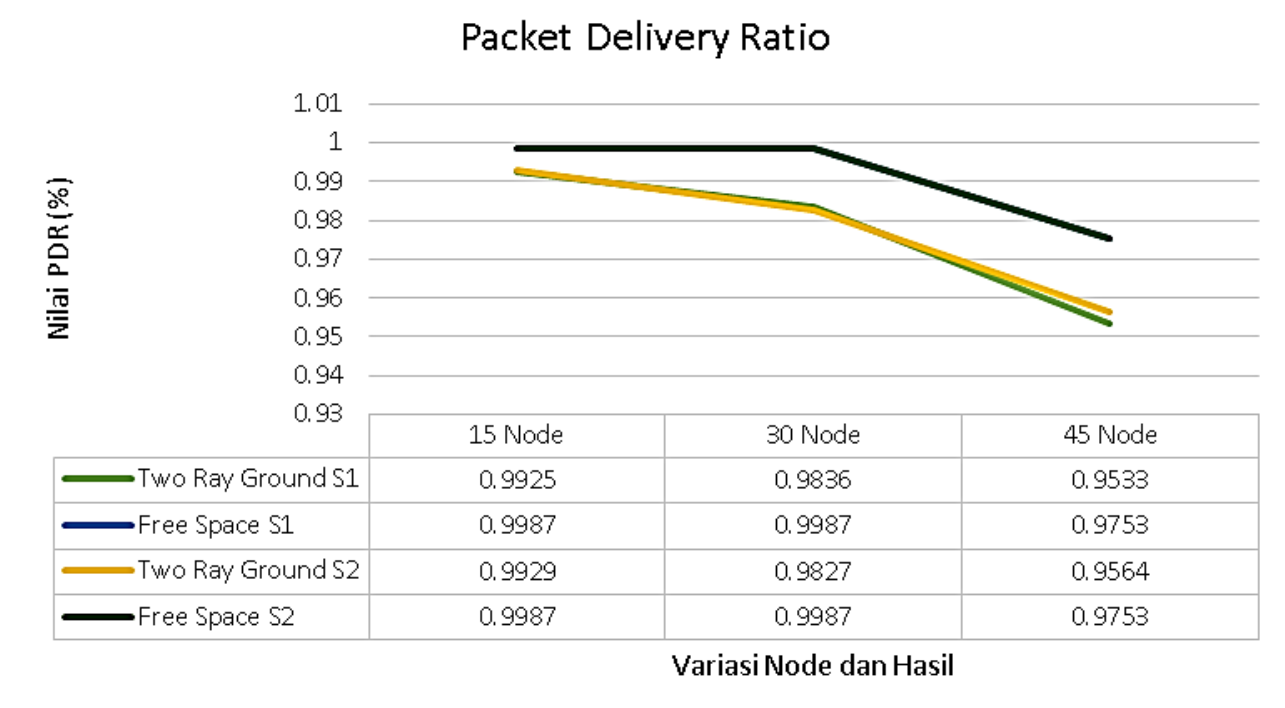

Gambar 4. Perbandingan Packet Delivery Ratio

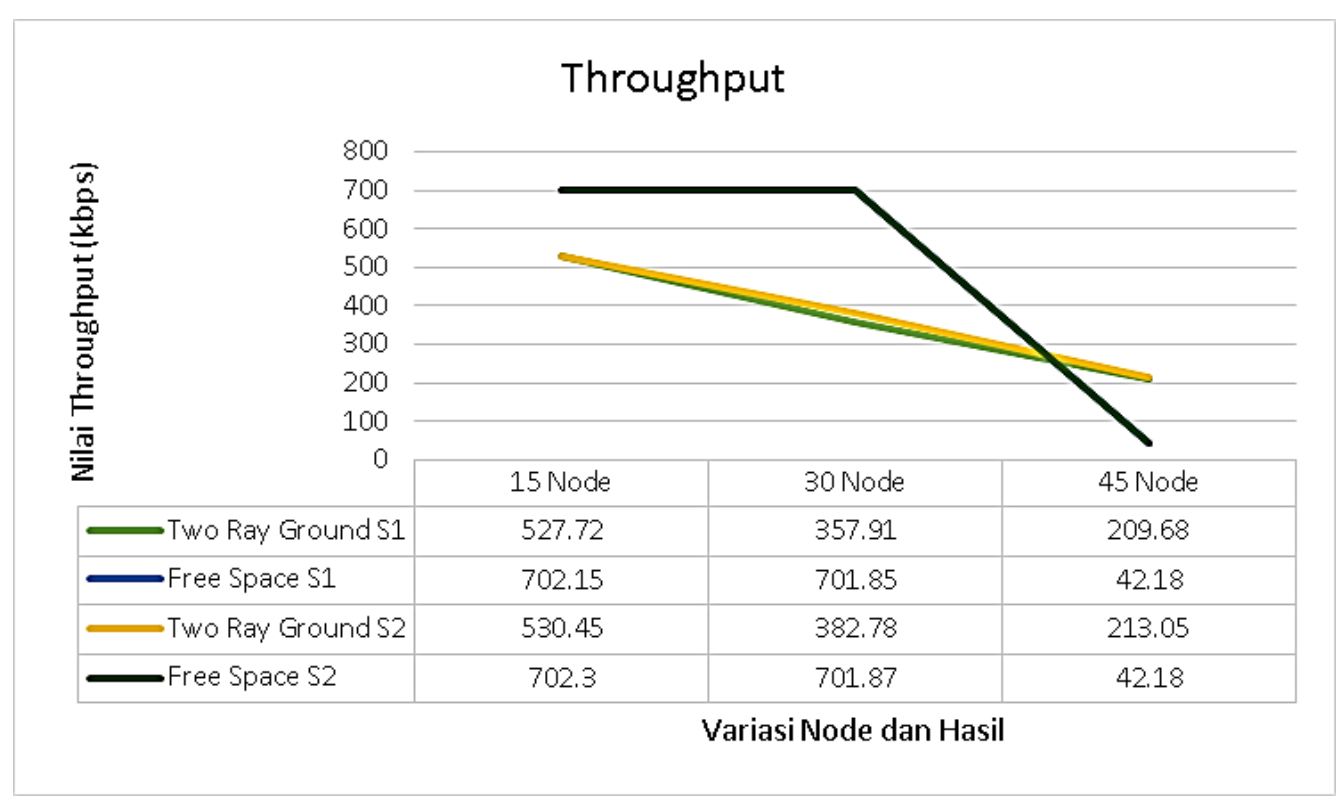

Gambar 5. Perbandingan Throughput

Pada Gmabar 5 menggambarkan bahwa QoS Throughput pada Propagasi Two Ray Ground mengalami grafik menurun ketika jumlah node semakin banyak. Propagasi Free Space mempunyai nilai yang tinggi dibandingkan Two Ray Ground, akan tetapi propagasi Free Space mengalami penurunan nilai yang drastis pada 45 node. Hal ini membuktikan bahwa propagasi Free Space dengan skenario yang telah ditentukan pada 30 node menjadi acuan dengan nilai Throughput yang stabil. Skenario yang ditentukan juga berpengaruh pada propagasi Two Ray Ground yang mendapatkan nilai Throughput yang berbeda, tetapi untuk propogasi Free Space tidak berpengaruh. Adapun selisih nilai Throughput pada kedua propagasi setiap variasi node yang ditentukan, diantaranya pada 15 node: $174.43 \mathrm{kbps}, 30$ node: $343.94 \mathrm{kbps}$, dan 45 node: $167.5 \mathrm{kbps}$.

\section{Penutup}

Setelah melalui tahap implementasi dan pengujian yang sesuai dengan rancangan dan skenario yang ditentukan, ada beberapa kesimpulan yang diambil dari implementasi dan hasil pengujian tersebut, selain itu juga ada saran untuk penelitian lebih lanjut.

REPOSITOR, Vol. 1, No. 2, Desember 2019: 69-78 


\subsection{Kesimpulan}

Berdasarkan hasil penelitian dalam skripsi ini, kesimpulan yang dapat diambil dari implementasi tersebut adalah sebagai berikut:

1. Jika ditinjau dari segi efisiensi nilai delay maka propagasi Free Space lebih baik dibandingkan dengan propagasi Two Ray Ground.

2. Hasil nilai jitter mengalami hal sama dengan nilai delay yaitu propagasi Free Space lebih baik dengan nilai rata-rata $0.1136 \mathrm{~ms}$ dan Two Ray Ground bernilai $0.1696 \mathrm{~ms}$.

3. Nilai PDR pada propagasi Free Space dan Two Ray Ground mendapatkan grafik yang menurun dengan variasi node yang ditentukan. Akan tetapi, propagasi Free Space mendapatkan rasio lebih besar dibandingkan dengan propagasi Two Ray Ground.

4. Hasil dari throughput lebih bagus dihasilkan dengan menggunakan propagasi Free Space dengan batas variasi 30 node, selebihnya mengalami penurunan nilai yang drastis. Dengan nilai rata-rata throughput pada Free Space adalah 482.06 kbps dibandingkan dengan Two Ray Ground yang hanya 365.10 kbps.

5. Suatu skenario juga berpengaruh pada nilai QoS pada propagasi Free Space dan Two Ray Ground.

6. Beberapa skenario pada nilai PDR pada propagasi Free Space memiliki nilai yang sama.

7. Suatu variasi node sangat berpengaruh pada nilai QoS.

\subsection{Saran}

Proses implementasi dan pengujian pada penelitian ini masih membutuhkan pengembangan lebih lanjut, saran yang dapat diberikan antara lain:

1. Analisis kinerja pada VANET ini tidak hanya terpaku pada propagasi Free Space dan Two Ray Ground saja, namun bisa di dilakukan pada propagasi lainnya.

2. Jumlah node dalam penelitian ini bisa dibuat lebih bervariasi lagi agar mendapatkan nilai QoS yang kompleks.

3. Dapat menerapkan protokol routing yang berbeda agar mendapatkan komparasi acuan yang lebih baik.

4. Dapat menerapkan simulasi mobilitas berdasarkan skenario lingkungan yang berbeda.

5. Membahas tentang aspek keamanan jaringan.

\section{Referensi}

[1] Data Jumlah Kecelakaan https://www.bps.go.id/linkTabelStatis/view/id/1415 diakses pada tanggal 30-03-2017

[2] Vehicular Ad Hoc Network http://kbj.if.its.ac.id/mengenal-teknologi-vanet/ diakses pada tanggal 30-03-2017

[3] M. singh Harmandeep singh, "Effect Of Black Hole Attack On AODV Routing Protocol In MANET," Int. J. Comput. Sci. Technol., vol. 2278-3091, no. may-june, pp. 43-46, 2013.

[4] A. N. Kitono and T. Y. Arif, "Evaluasi Kinerja VANET pada Berbagai Model Propagasi Menggunakan Simulator Jaringan NS-3."

[5] M. N. Ns-, B. Bahteradi, and R. Anggoro, "Studi Kinerja Multipath AODV dengan," vol. 5, no. 2, 2016.

[6] Jenis jaringan ad hoc http://www.materi-it.com/2014/11/jenis-jaringan-ad-hoc.html diakses pada tanggal 24-09-2017

[7] K. Pandey, S. K. Raina, and R. S. Rao, "Performance Analysis Of Routing Protocols For Vehicular ADHOC Networks Using Ns2 / sUMO," vol. 8491, pp. 844-848, 2015.

[8] R. Anggoro, "Studi Perbandingan Kinerja Model Transmisi Two Ray Ground dan Nakagami pada OLSR di," vol. 5, no. 2, 2016.

[9] E. H. Harahap, "Analisis Performansi Protokol AODV ( Ad Hoc On Demand Distance Vector ) dan DSR ( Dynamic Source Routing ) Terhadap Active Attack Pada MANET ( Mobile Ad Hoc Network ) Ditinjau dari Qos ( Quality Of Service )," Tugas Akhir Telkom Univ., vol. 34, no. 1, p. 9, 2014.

[10] SUMO http://www.dlr.de/ts/en/desktopdefault.aspx/tabid-9883/16931_read-41000/ diakses pada tanggal 24-09-2017 
REPOSITOR, Vol. 1, No. 2, Desember 2019: 69-78 